\title{
Examining leadership as a strategy to enhance health care service delivery in regional hospitals in South Africa
}

This article was published in the following Dove Press journal: Journal of Multidisciplinary Healthcare

\section{Sagaren Govender Cecile N Gerwel Proches Abdulla Kader}

Graduate School of Business and Leadership, University of KwaZuluNatal, Durban, South Africa
Correspondence: Cecile N Gerwel Proches

Graduate School of Business and Leadership, University of KwaZulu-Natal, Private Bag X5400I, Durban 4000, South Africa

Tel +273I 2608318

Email gerwel@ukzn.ac.za
Background: Four public hospitals in South Africa, which render both specialized and nonspecialized services to thousands of patients, were examined to determine the impact of leadership on health care service delivery. These hospitals were inundated by various problems that were impacting negatively on health care service delivery.

Purpose: This research study aimed to gain a comprehensive understanding of the challenges, complexities and constraints facing public health care in KwaZulu-Natal (KZN) and to examine leadership as a strategy to enhance healthcare service delivery with a particular focus on four regional hospitals in the KZN Province.

Methods: The mixed-method research approach was utilized. Purposive sampling and stratified random sampling were employed in the research setting, and in-depth, semistructured interviews and questionnaires were used to collect data. Data were analyzed using the Nvivo computer software package for in-depth interviews and the Statistical Package for the Social Sciences (SPSS) software for the quantitative analysis.

Results: The research findings showed that the current leadership framework adopted by the health care leaders in regional hospitals in KZN is weak and is contributing to poor health care service delivery.

Conclusion: This study, therefore, aimed to address the current challenges and weaknesses that are impacting negatively on health care service delivery in regional hospitals in the KZN Province and made recommendations for improvement.

Keywords: health care service delivery, public hospital, leadership, South Africa

\section{Introduction}

The study was conducted in four regional hospitals in the KwaZulu-Natal (KZN) Province, South Africa. The identity of the hospitals is not mentioned because of confidentiality agreements and is hereafter referred to as "the hospitals". In terms of the Constitution of the Republic of South Africa Act No. 108 of 1996, the Department of Health is mandated to ensure that optimal and professional health care services are provided to all citizens of the country and from various cultural backgrounds. ${ }^{1}$ According to the White Paper on the Transformation of the Public Service (1997), the delivery of health care to the citizens of the Republic should be guided by the principles embodied in the Batho Pele (a Sotho term) framework, meaning "People First". ${ }^{2}$ Public hospitals, therefore, play a critical role in delivering health care to the population of this country. However, strong allegations have been made by the media on a myriad of negative issues specifically relating to health care service delivery issues at provincial hospitals in KZN. ${ }^{3}$ Allegations of fraud and corruption, lack of modern 
medical equipment and medical supplies, critical staff shortages, high mortality and morbidity rates, poor management, long patient queues, poor infrastructure and the high rate of litigation due to clinical negligence reflect that the health care system in South Africa is in dire need of urgent reforms. ${ }^{4,3}$

Senanayake emphasized that:

The world over - and in developing countries in particularthe manner in which health services are delivered leaves much to be desired. In these situations, the people who suffer most are those in the poorest strata of society. ${ }^{5}$

It is against this background that the planned research attempted to identify the key challenges that were hampering health care service delivery at the four regional hospitals in the KZN Province and examined leadership as a strategy to enhance health care service delivery at these hospitals. The purpose of this explorative study of examining leadership as a strategy to enhance service delivery at the chosen four regional hospitals in the KZN Province was to provide guidelines for improved health care service delivery within the ambits of existing legislations in the Department of Health. Ndlovu clearly pointed out that the South African health care system is suffering because of a lack of efficient and effective service delivery, therefore lacking credibility. ${ }^{4}$

The negative picture of the South African health care system painted by the media negates the ideals of the Constitution of the Republic of South Africa, the Patient Rights Charter, the Bill of Rights as well as the Batho Pele Principles. In her study, Naidoo also indicated that the Department of Health is mandated to develop an integrated and a comprehensive health care system that could provide affordable and accessible health care to all South Africans. ${ }^{6}$ Therefore, it is crucial that the South African public have equitable and accessible health care, which is deemed a fundamental right for all citizens.

This study, in particular, focused on the leadership principles employed specifically at the selected four regional hospitals in the KZN Province primarily aimed at improving health care service delivery. Previous studies have indicated that tardy organizational performance is related to poor leadership, consequently affecting service delivery. ${ }^{3}$ The writer also observed that factors such as poor governance, political struggles, communication breakdowns, poor client services and inefficient management could cause poor service delivery. Naidoo also pointed out that:

In the Health Summit of 2001, the Minister of Health indicated that policy implementation issues with respect to slow service delivery are critically affected by leadership decision-making and leadership commitment. ${ }^{6}$
The combined clinical and organizational challenges that inundate health care organizations on a daily basis require strong leaders in all spheres and at all levels. In McAlearney's study, it was emphasized that great leaders are transformational, who are able to motivate and empower their followers. ${ }^{7}$ They also articulate the organizational vision, conform to values and norms, build trust and motivate followers to achieve organizational goals. However, McAlearney argues that "Yet a sense of how to best develop these great, transformational leaders is far from established, especially in health care organizations." " Naidoo and Xollie also highlight a myriad of human resource challenges such as personnel conflicts, lack of skills and experience, and leadership and management capacity that continue to pose problems in the public service, of which the KZN Health Department is also a major role-player. ${ }^{8}$

It is particularly important for health care organizations to have the right kind of leadership in order to cope with the complexities and competitiveness that prevail in such environment. McAlearney contended that:

[...] despite growing support for the importance of leader-

ship development practices across industries, little is known

about leadership development in health care organizations. ${ }^{7}$

Naidoo also cited Miller wherein it is indicated that training and development in public sector organizations only focus on certain aspects of managerial leadership. ${ }^{9}$ In Boaden's study, it was highlighted that research on leadership development concludes that although leadership styles can impact significantly on performance and outcomes in the social sciences, there is little evidence of this work in the health care system. ${ }^{10}$ The evolution of health care to evidence-based practice also calls for more research in leadership development in the health care sector. ${ }^{10}$

Although there are considerable literature on public sector service delivery that focuses mainly on municipalities, education and public health, it has been noted that insufficient research has been conducted in respect of leadership versus public health care services, specifically at the regional hospitals in KZN Province. ${ }^{11,12,4}$ In the South African context, there is a critical need for effective leadership at regional hospitals in order to contribute to improving service delivery initiatives. In Boaden's study, it was emphasized that effective leadership could be a key factor toward the modernization of today's health care services, because better leadership can contribute to improved patient care and effective work practices for staff. ${ }^{10}$

The South African government has a constitutional mandate to execute its functions in the most effective and efficient manner, necessitating investment in capacity building and 
skills development for public servants in order to contribute to the smooth and effective functioning of government departments. ${ }^{4}$ Health care service delivery at provincial hospitals in KZN is in dire need of urgent reforms, because of the inability of these hospitals to provide quality health care in terms of the South African Constitution and the Patients Right Charter. ${ }^{4}$ It is critically important that the KZN Department of Health apply effective leadership principles for the future development of health care leaders. This study, therefore, aimed to examine leadership at the targeted four regional hospitals in the KZN Province and to determine how this could contribute to improving health care service delivery for the vast number of patients that are reliant on public health care.

A thorough understanding of leadership principles in regional hospitals in the KZN Province and its application could enhance service delivery initiatives at these hospitals. The primary aim of this research was to examine the leadership in four regional hospitals in the KZN Province and to determine the impact that this could have on improving and sustaining service delivery at the respective regional hospitals. According to Schmitt, leadership has been recognized as an important driver of quality health care outcomes and patient safety. ${ }^{13}$

Govender identified various challenges relating to leadership at a public hospital in KZN that impacted negatively on health care service delivery. ${ }^{3}$ According to Naidoo, the Minister of Health in his Health Summit speech of 2001 declared that leadership commitment and leadership decision-making are critically affecting the implementation of policies relating to poor service delivery in the health department. ${ }^{6}$

Govender stressed that innovative leadership-related strategies are urgently needed in order to sustain viability of modern health care organizations and to enable them to cope with the impending challenges of providing effective, efficient and quality health care. ${ }^{3}$ Such leadership is direly needed in the public health care system in South Africa. Naidoo also emphasizes that:

There is a major need for investment in public service training, leadership development and capacity building, as an indispensable precondition for a sustainable public service for effective service delivery. ${ }^{6}$

Jasper and Jumaa refer to Burns' (1978) definition of transformational leadership as a process where people engage with one another in a manner where leaders and followers elevate each other to greater heights of morality and motivation. ${ }^{14}$ Transformational leadership has also been shown to be linked to job satisfaction and organizational innovation. ${ }^{15}$ Transformational leadership is essentially about change. ${ }^{16}$

It is particularly important that the leaders in public health care organizations mobilize and inspire their teams in order to respond to the challenges that face them on a daily basis. ${ }^{17}$ This type of leadership, therefore, requires personal commitment and decisive action in order to respond to challenges at the grassroots level.

Fealy et al describe leadership as a complex social process that emerges from the collective capacity of staff members that can assume leadership roles and responsibilities in an organization. ${ }^{18}$ Although it is argued that a myriad of published leadership literature is found to be lacking empirical justification and is anecdotal, researchers did reach consensus on leadership as a process that is concerned with intrapersonal and interpersonal attributes and behaviors and also recognizing leadership development as context bound. ${ }^{19}$

Jooste suggests that leadership development in the health care sector aims to:

- provide guidelines for developing health care leaders within the context of health care goals

- facilitate improving leadership across all levels in the organization

- continuously encourage health professionals to develop their leadership skills and knowledge

- ensure that the development of leadership capabilities is an ongoing process and fully integrated into the working environment. 20

Effective leadership is crucial for introducing change successfully, and such change needs to be managed well through proper planning, organizing and control. Charlton suggests that leaders and followers must have a belief in their efforts to effect change in order to cope with any change initiatives that would benefit themselves and the organization as a whole. ${ }^{21}$ The increasing complexity in public health care and the magnitude of the problems that permeate health care organizations make one's expectations unrealistic to consider that a single approach can solve all the problems. ${ }^{22}$ A multifaceted strategy should, therefore, be adopted in order to implement change in an organization. The hallmark of the health care profession is that the environment is continuously changing. However, leaders must also recognize that change can bring challenges. Therefore, Jooste asserts that leaders should continuously monitor the pace and patterns of change in order to ensure collaborative working relationships with health care professionals primarily aimed at providing health care services. $^{20}$ 
Grol et al stated that change management plays a critical role in health care. ${ }^{22}$ Change management and quality improvement programs in health care should form the basis of all clinical and management training programs. ${ }^{23}$ Although change management, as a science, is not relatively new, there are still much expectations from the people for quality and safe health care. ${ }^{23}$

Wong and Cummings referred to Avolio et al's (2004) view that challenging phenomena such as corporate scandals, terrorism, threatening diseases such as the flu pandemic and the revenue crisis demand leaders to display higher levels of integrity, accountability and character. ${ }^{23}$ Therefore, there is renewed emphasis on focusing on the ethical and moral aspects of leadership, thus envisioning the concept of authentic leadership. Wong and Cummings also draw on Kernis' (2003) definition of authenticity as a psychological construct of knowing, accepting and behaving in accordance with one's preferences, beliefs, values and emotions. ${ }^{23}$

Kerfoot refers to Goffee and Jones' (2005) point that leaders cannot define themselves as authentic leaders, but the people who share experiences with the leader must ascribe such attribute to the leader. ${ }^{24}$ People, therefore, can perceive the authenticity of leaders through the leader's sincerity, honesty and integrity. According to Kerfoot, authentic leaders exhibit their core values in their functional domains, visualizing themselves as stewards and servants, leading from their hearts as well as from their heads, while building stability and sustainability in their organizations. ${ }^{24}$ Klenke referred to Avolio et al's (2004) definition of authentic leaders as individuals who are fully aware of their own thinking patterns and behaviors, and are constantly aware of their own high moral values and standards as well as that of others, including their strength, knowledge and the context in which they function. ${ }^{25}$

\section{Methods}

In this study, a mixed-method research methodology was used in order to examine the research objectives. The mixed-method methodology included both the qualitative and quantitative research approaches for this study. The aim was to gather data on a variety of aspects pertinent to the study using the mixed-method approach in order to construct a holistic picture of the situation. In this study, leadership takes place in the real world, specifically in a complex health care environment. Purposeful sampling was employed for the qualitative approach of this mixed-method study. The targeted research sites and respondents for this study were purposefully selected at only four Regional Hospitals in KZN. Multiple perspectives as well as diverse views and opinions are critically important for achieving a deeper understanding of the research questions and objectives. The targeted sample population for the qualitative phase comprised mainly of senior managers from each regional hospital. The total number of respondents for the qualitative approach was 15 . The researcher conducted semistructured, in-depth interviews with the respective senior managers in the offices of their respective hospitals and on scheduled appointments during the period December 28, 2015, to April 13, 2016.

In the quantitative phase of this study, stratified random sampling was employed where the population was divided into homogeneous groups that had subjects that shared similar characteristics, for example, occupational categories, gender, age or home language. The strata of the samples that was exclusively used in the quantitative phase of the study included lower-level managers and employees from different occupational categories such as medical, nursing, finance, systems, supply chain management, pharmacy, human resource management and radiology. These lower-level managers and employees from the different occupational groupings were chosen primarily to establish their views and perspectives on being led by the executive leadership at each regional hospital. The total sample population consisted of 380 lower-level managers and employees who were from the targeted four regional hospitals in KZN. In the quantitative approach of this empirical study, questionnaires were used as a method for data collection. The questionnaire was validated and questions focused on key issues related to leadership and health care service delivery in regional hospitals. The researcher administered 380 questionnaires to the research participants during the period March 1 to April 15, 2016, as indicated in Table 1.

The use of questionnaires as a form of quantitative methodology in this study broadened the scope of the phenomenon being studied.

The Nvivo computer software package was used for analysis of the qualitative data emanating from the study. For the quantitative phase, both basic descriptive statistics and inferential statistics were used to analyze the data and answer the specific research objectives. The computer software package, Statistical Package for the Social Sciences (SPSS), was used to present the data collected in this study. The researcher ensured that adequate measures were put in place in order to ensure reliability, trustworthiness, validity and minimal bias in the collection of data. The researcher took into account the 
Table I Distribution of study participants

\begin{tabular}{|c|c|c|}
\hline Hospital & Occupational categories & $\begin{array}{l}\text { Participants } \\
\text { (n) }\end{array}$ \\
\hline Hospital A & Medical: medical officers & 6 \\
\hline Hospital A & Dental: dentists & 5 \\
\hline Hospital A & Pharmacy manager & I \\
\hline Hospital A & Pharmacists & 2 \\
\hline Hospital A & Nursing: unit managers & 5 \\
\hline Hospital A & Nursing professional nurses & 10 \\
\hline Hospital A & Nursing: staff nurses & 10 \\
\hline Hospital A & Nursing educators & 4 \\
\hline Hospital A & Human resources: assistant manager & $\mathrm{I}$ \\
\hline Hospital A & Human resources officers & 5 \\
\hline Hospital A & Systems: assistant manager & 1 \\
\hline Hospital A & Administration clerks & 5 \\
\hline Hospital A & Radiography: assistant director & 1 \\
\hline Hospital A & Radiographers & 5 \\
\hline Hospital A & Physiotherapy: manager & $\mathrm{I}$ \\
\hline Hospital A & Physiotherapists & 5 \\
\hline Hospital A & Occupational therapy: manager & $\mathrm{I}$ \\
\hline Hospital A & Occupational therapists & 3 \\
\hline Hospital A & Speech and audiology: manager & 1 \\
\hline Hospital A & Audiologists & 3 \\
\hline Hospital B & Medical: specialists & 2 \\
\hline Hospital B & Medical: medical officers & 13 \\
\hline Hospital B & Dental: chief dentist & I \\
\hline Hospital B & Dental: dentists & 5 \\
\hline Hospital B & Pharmacist manager & 1 \\
\hline Hospital B & Pharmacists & 3 \\
\hline Hospital B & Nursing: unit managers & 5 \\
\hline Hospital B & Nursing: professional nurses & 10 \\
\hline Hospital B & Nursing: staff nurses & 10 \\
\hline Hospital B & Nurse educators & 5 \\
\hline Hospital B & Human resources: assistant managers & 2 \\
\hline Hospital B & Human resources officers & 3 \\
\hline Hospital B & Systems: assistant manager & 1 \\
\hline Hospital B & Systems: administration clerks & 5 \\
\hline Hospital B & Supply chain management: manager & 1 \\
\hline Hospital B & Supply chain clerks & 5 \\
\hline Hospital B & Radiography: assistant director & $\mathrm{I}$ \\
\hline Hospital B & Radiographers & 6 \\
\hline Hospital B & Physiotherapy: manager & 1 \\
\hline Hospital B & Physiotherapists & 5 \\
\hline Hospital B & Occupational therapy: manager & 1 \\
\hline Hospital B & Occupational therapists & 4 \\
\hline Hospital B & Speech and audiology: manager & 1 \\
\hline Hospital B & Audiologists & 4 \\
\hline Hospital B & Health technology technicians & 3 \\
\hline Hospital C & Medical: specialists & 3 \\
\hline Hospital C & Medical physicist & 2 \\
\hline Hospital C & Pharmacy manager & 1 \\
\hline Hospital C & Pharmacists & 9 \\
\hline Hospital C & Nursing: unit managers & 10 \\
\hline Hospital C & Nursing: professional nurses & 20 \\
\hline Hospital C & Nursing: staff nurses & 20 \\
\hline Hospital C & Human resources: assistant managers & 2 \\
\hline Hospital C & Human resources officers & 3 \\
\hline Hospital C & Supply chain management: manager & 1 \\
\hline Hospital C & Supply chain officers & 2 \\
\hline
\end{tabular}

(Continued)
Table I (Continued)

\begin{tabular}{|c|c|c|}
\hline Hospital & Occupational categories & $\begin{array}{l}\text { Participants } \\
\text { (n) }\end{array}$ \\
\hline Hospital C & Finance: manager & I \\
\hline Hospital C & Finance: senior finance officers & 3 \\
\hline Hospital C & Finance services officers & 6 \\
\hline Hospital C & Radiography: assistant director & 1 \\
\hline Hospital C & Radiographers & 12 \\
\hline Hospital C & Physiotherapy: manager & 1 \\
\hline Hospital C & Physiotherapists & 4 \\
\hline Hospital C & Occupational therapy: manager & I \\
\hline Hospital C & Occupational therapists & 2 \\
\hline Hospital C & Speech and audiology: manager & I \\
\hline Hospital C & Audiologists & 3 \\
\hline Hospital C & Health technology technicians & 4 \\
\hline Hospital D & Medical specialists & I \\
\hline Hospital D & Medical officer & I \\
\hline Hospital D & Dental: chief dentist & I \\
\hline Hospital D & Dental: dentists & 5 \\
\hline Hospital D & Pharmacy: manager & I \\
\hline Hospital D & Pharmacists & 6 \\
\hline Hospital D & Nursing: unit managers & 6 \\
\hline Hospital D & Nursing: professional nurses & 10 \\
\hline Hospital D & Nursing staff nurses & 5 \\
\hline Hospital D & Nurse educators & 10 \\
\hline Hospital D & Human resources: assistant manager & I \\
\hline Hospital D & Human resources officers & 14 \\
\hline Hospital D & Supply chain management: manager & 1 \\
\hline Hospital D & Supply chain officers & 3 \\
\hline Hospital D & Finance: assistant manager & I \\
\hline Hospital D & Finance officers & 4 \\
\hline Hospital D & Administration clerk & I \\
\hline Hospital D & Radiography: assistant director & I \\
\hline Hospital D & Radiographers & 4 \\
\hline Hospital D & Physiotherapy: manager & I \\
\hline Hospital D & Physiotherapists & I \\
\hline Hospital D & Occupational therapy: manager & I \\
\hline Hospital D & Occupational therapists & I \\
\hline Hospital D & Speech and audiology: manager & I \\
\hline Hospital D & Audiologists & 2 \\
\hline Hospital D & Maintenance: artisan foremen & II \\
\hline Hospital D & Librarian & I \\
\hline Total & & 380 \\
\hline
\end{tabular}

ethical considerations in this study and demonstrated high levels of professionalism and strict adherence to moral and ethical standards during his interaction with the research subjects. Gatekeeper letters were obtained from the participating hospitals and ethical clearance approval was obtained from the University of KwaZulu-Natal. Approval for the research was granted by the KZN Department of Health Research Committee and the Humanities and Social Sciences Research Ethics Committee of the University of KwaZulu-Natal. Participants were requested to provide informed consent before being interviewed and having completed questionnaires. 


\section{Results and discussion}

\section{Health care service delivery challenges}

The study identified numerous service delivery challenges in the selected four regional hospitals, which included:

- Overcrowding of patients because of an increasing catchment population from informal settlements,

$[\ldots]$ in terms of patients and services there is a huge influx of primary health care patients and that causes a gridlock at the casualty and MOPD (medical outpatients). [Respondent (R)9]

- High turnover rate of in-patients that contributed to an increase in the bed occupancy rates, consequently regional hospitals experienced shortages of beds for patient admissions,

- Stringent implementation of cost containment measures by the KZN Department of Health has contributed to limited financial resources available for operational activities,

The first service delivery challenge is the budget constraints for filling of certain critical posts in both the systems component and the hospital as a whole. [R4]

- Lack of human resources such as doctors, nurses and allied health therapists as well as support services staff such as cleaners, porters, drivers and security officers is causing increasing workloads, low staff morale and negative attitudes from the existing staff,

The problem is now of unfreezing of posts, whenever someone leaves, it is a major challenge that we are facing; the delay is unfreezing, the fact that these posts need to go to the CFO and then to the Premier especially as we call them the vital posts. [R12]

- Critical shortages of professional staff such as doctors and nurses in the clinical settings are also resulting in longer patient waiting times,

- The infrastructure in the regional hospitals, mainly buildings, is old and often needs maintenance and refurbishments. The health care professionals considered such aging infrastructure as an impediment to health care service delivery operations,

- Regional hospitals were continuously experiencing shortages of essential supplies such as pharmaceuticals, bandages, gauze, syringes, medicines, drugs and linen,

For example, the procurement of surgical sundries for theatre, where the usage is high and late delivery, or sometimes you end up with no stock. [R4]
Frequently, we find that medications are not able to be secured by central supplies, and with the result we cannot promise or guarantee the patients when they going to get the supplies, $[\ldots]$ often they make more frequent visits in the hope that we going to get medication. [R2]

- The technology in medical equipment in regional hospitals was old and outdated, and such equipment was often nonfunctional and needed repairs and maintenance continuously,

We have outstanding equipment for specialised services for the last three or four years that haven't come through. [R12]

- Generally, there was lack of support from senior management at the Head Office level.

\section{Leadership-related interventions to enhance health care}

The study established that despite the multitude of challenges that inundate regional hospitals in KZN, leadership-related interventions were crucial for enhancing health care service delivery. Decision-making and leadership approaches by the health care leaders were considered significant for achieving health care goals in regional hospitals. According to Naidoo, strong, capable leaders strive to achieve service delivery goals despite the lack of capacity and resources. ${ }^{6}$ The study's finding showed that leadership was an important core competency for health care leaders whereby it was suggested that such leaders must be transformational, espousing innovation and creativity toward achieving strategic goals and objectives. "There are so many things that leadership can change in the health care system". [R6] "You must have leadership change". [R4]

In the context of this study, it was revealed that despite the evolution of management practices in contemporary health care, there still exist a significant number of old school managers in the KZN Department of Health. The evidence from the findings also indicated that senior managers in the KZN Department of Health lacked knowledge and fieldwork experience on health care service delivery, and there was inconsistent application of the public service code and procedures, thus compromising service delivery on ground levels. The study, therefore, suggested that there is a dire need for strong leadership at all levels of the service delivery chain in order to ensure optimal and quality health care for the vast majority of patients. This is evidenced in the quantitative findings when $73 \%$ (mean score $=3.75$ ) of 
the respondents agreed that leadership plays an important role in optimizing organizational performance at regional hospitals.

\section{Capacities to enhance health care in regional hospitals}

It emerged from the study that the respective health care workers were lacking in capacity that is critically needed for achieving health care outcomes in regional hospitals in KZN. The study brought to the fore the importance of the skills and competencies of health care professionals that was considered crucial for executing their clinical functions relevant to patient care.

$[\ldots]$ in certain areas like ICU, you'll need specialists in ICU, we use surgeons to run our ICU and one of the reasons is because we don't have the money to create a post and also I think there will be a shortage of them. [R1]

The study's results (qualitative) showed that regional hospitals were facing dire shortages of skilled health care professionals such as general specialists in surgery, medicine, psychiatry, obstetrics and gynecology.

I think more training needs to be offered dealing with the context of the hospital environment [...]. [R8]

Studies have shown that it is important to have the right number of people with the prerequisite skills in order to meet current and future human resource requirements, as well as promoting human resource development through education and training for optimizing performance. ${ }^{26,9}$

Strategies such as training, coaching and staff empowerment were revealed in this study as crucial for capacity building of health care workers in regional hospitals. The quantitative results indicated that $71 \%$ (mean score $=$ 3.65 ) of the respondents agreed that managers supported employee development primarily through on-the-job training, mentoring, coaching and problem-solving. The study also emphasized the need to build capacity relating to leadership and management in regional hospitals because it emerged that junior managers are often appointed to act in critical vacant senior management posts, which poses problems when staff members lack the skills and competencies to act in higher posts. In Naidoo's study, it was argued that the South African public sector organizations are facing dire shortages of management capacities as well as the lack of skills and experience resulting in poor service delivery to the citizens. ${ }^{9}$

\section{Leadership styles adopted by health care leaders}

The study identified leadership as a key competency of health care leaders in regional hospitals, which is considered crucial for influencing those that they lead toward achieving the health care goals. The quantitative results indicated that $78 \%$ (mean score $=3.90$ ) of the respondents agreed that managers are good leaders when they communicate achievements and service accomplishments to all staff members.

The evidence from this study further revealed that a democratic or participative leadership style was essential in a dynamic and uncertain health care environment because such leaders encouraged collaboration, consultation and stakeholder engagements and they focused on problemsolving on ground level.

To be an effective leader, you generally need to be a democratic leader but at times it calls for autocratic leadership as well. [R5]

When one becomes a consultative manager, that is someone that is democratic in the way they make decisions, you must also possess those qualities [...], having trust for your staff, respect for your staff, respect for human dignity and so on. [R15]

However, it has also emerged from the study that due to cultural diversity in regional hospitals, managers were using integrated leadership approaches in the workplace, where both autocratic and democratic leadership styles were prevalent. Transformational leadership was one of the leadership styles that was revealed as significant for managers in addressing the complex issues and challenges that prevail in regional hospitals, as well as for the implementation of various policies pertinent to health care.

[...] an institution such as this would really benefit a lot from having a transformational leader, definitely, because of all the challenges that need innovative approaches and also then being able to take people along. [R10]

According to Yukl, transformational leaders encourage innovation and creativity within the team, emphasizing the need for trust, respect, loyalty and admiration among team members. $^{27}$

\section{Developing leadership capabilities for health care workers}

The evidence from the study showed that various factors such as support by senior management, funding and appropriate 
internal systems and processes play an influential role in the development of leadership capabilities for managers in regional hospitals.

For leader development, we need, if we are talking about factors, we need resources: to be able to take people but also we need a system that is receptive of changes. [R10]

To develop future managers, you need to support them in their initiative, you must not be a dictator, you must be able to give future supervisors the opportunity to view their opinions [...]. [R4]

The findings from other studies revealed that the development and mentoring of managers in senior management roles was crucial for improving leadership competencies, which could contribute to improving organizational performance. ${ }^{6,4}$ It has also emerged from the study that lean thinking and quality management programs were being implemented as developmental strategies for managers in some regional hospitals. Lean thinking is used as a means to promote work flow and reduce wastages through the organization of complex processes and activities. The application of lean thinking is applied predominantly in the manufacturing sector. In the context of this study, lean thinking was used by some clinicians as a strategy to resolve certain complex health care issues. The study also brought to the fore the importance of leadership development programs that was essential for developing the leadership skills of senior managers in regional hospitals.

I would say if money was available, we would have invested in getting some good dynamic, either companies or individuals, to come and do some leadership courses, where we can get things like team building techniques [...]. [R5]

The quantitative findings also revealed that managers will encourage the development of their staff on leadership (mean score $=3.57$ ). However, the study revealed that such opportunities were limited because of stringent cost containment measures imposed by the KZN Department of Health.

\section{Recommendations}

The study suggested that it is critically important to address the challenges and weaknesses that prevail in regional hospitals in the KZN Province, which could impact on the ability of these hospitals to provide effective, efficient and quality health services to the vast majority of patients in the future. The below recommendations are made based on the study's findings.

\section{Developing leadership capabilities}

There is an urgent need to develop and train all health care managers, including clinicians such that they can become effective managers and leaders. The training and development of all health care managers in regional hospitals can be achieved by nominating the respective officials for attending leadership development programs at accredited training institutes in South Africa. Leadership is critical for improving health care service delivery in regional hospitals in the KZN Province; therefore, it is imperative that all health care managers should reflect their leadership skills and competencies in their daily work activities. Training interventions can also be focused on the value of drawing on the systems perspective through popular works such as the Fifth Discipline.

\section{Integrating leadership approaches}

The study suggests that an integrated leadership approach is required to enhance health care service delivery in regional hospitals. It is particularly important that such leadership approaches will take into account the diversity of the workforce and should be flexible and adaptable to changing circumstances, thus contributing to effectiveness and efficiency in terms of health care service delivery. The current leadership framework that dominates the respective health care facilities in KZN demands an integrated leadership approach where the respective managers can use appropriate leadership styles in accordance with the situation.

\section{Strengthening human resource capacity}

The study brought to the fore that lack of human resource capacity at regional hospitals, particularly critical professional staff and some support staff, was regarded as a key factor for achieving optimal health care at the facilities. The human resource management processes, particularly recruitment and selection, should strive to select candidates for critical posts with the appropriate skills and competencies that would contribute to delivering the mandate of the KZN Department of Health. It is crucial that the regional hospitals appoint and promote health care workers based on their professional qualifications and the level of their skills and competencies. It is imperative that the KZN Department of Health make adequate funding available to the facilities in order to unfreeze, advertise and fill all critical vacant professional posts and key support services posts.

\section{Strengthening performance management of managers}

The performance management system for all managers in regional hospitals needs to be strengthened such that it is 
aligned to the key strategic goals and annual performance plans of the KZN Department of Health. The Head of the KZN Department of Health, as well as all CEOs of regional hospitals, should be responsible for strengthening performance management at institutions and ensuring its implementation. The performance management of managers at the respective health care facilities can be reinforced by increasing the focus on health care outcomes and achievements. The current system for assessing individual performance must be strengthened in order to improve the performance management of managers in all regional hospitals.

\section{Embracing the significance of Batho Pele 'people first' principles}

The Batho Pele (people first) principles in all public sector organizations are aimed at providing optimal service delivery to all citizens residing in South Africa. In the context of health care, the implication is that all activities relating to health care service delivery must be directed toward satisfying the health care needs of the public. The study suggests that there is an urgent need to improve health care service delivery in regional hospitals to the extent where the patients as customers are satisfied with the services rendered. It is imperative that the relevant structures in regional hospitals are strengthened in order to promote transparency and accountability. The increasing demands for health care services from the public require innovation and creativity from health care workers such that they can meet their expectations and health care needs. The study recommends that regional hospitals in KZN should satisfy the basic principle of providing effective, efficient and quality health care to the public in terms of the Batho Pele principles.

\section{Provision of adequate infrastructural support and equipment}

The study suggested that a lack of adequate infrastructural support and malfunctioning medical equipment compounded the service delivery challenges that were faced by health care leaders at the respective regional hospitals in KZN. There is an urgent need to ensure that the baseline support with regard to adequate buildings and medical equipment at regional hospitals is provided in order to assist health care workers to execute their roles and responsibilities effectively and efficiently. To achieve this, it is imperative that the KZN Department of Health develop infrastructure improvement plans as well as medical equipment replacement plans that would support the improvement to existing buildings as well as the procurement of new medical equipment where necessary.

\section{Strengthening monitoring and evaluation systems}

The monitoring and evaluation systems in regional hospitals must be strengthened in order to ensure that health care service delivery goals are achieved. A monitoring and evaluation component must be established at each regional hospital primarily to monitor performance, evaluate findings and make recommendations for improvement. The performance of hospitals in relation to achieving objectives must be measured against set standards, targets and timelines, and the respective senior managers must take corrective action when deviations are detected. Performance indicators can be useful in determining whether health care service delivery objectives are being attained in regional hospitals.

\section{Future research}

Further research could be extended to all tertiary hospitals in the province, which could offer additional insights into the topic. Another interesting area for future research would be to analyze the impact of leadership in relation to health care service delivery at all rural regional hospitals in KZN. The study brought to the fore the importance of integrating different leadership styles in different situations in the health care context. For this reason, it is recommended that future research should focus on examining integrated leadership approaches and the associated impact on public health care in the South African context. This study highlighted the need for leadership development at all management levels involved in public health care organizations; thus, further research should focus on leadership development, specifically in public hospitals in KZN.

\section{Conclusion}

The recommendations based on the research findings by the researcher could make a significant contribution toward improving health care service delivery in regional hospitals in KZN. The study highlighted numerous service delivery challenges and weaknesses in regional hospitals that need urgent leadership-related interventions in order to ensure optimal health care service delivery to the population. The study recommends that an integrated leadership approach in regional hospitals is critically important to improve health care service delivery, taking into account the economic, social, psychological and cultural diversities of the 
population. Transformation of the public health care system in South Africa is desperately needed, and it is anticipated that this study will make a positive contribution toward transforming regional hospitals into effective, efficient, innovative and responsive institutions that seek to improve health care service delivery.

\section{Disclosure}

The authors report no conflicts of interest in this work.

\section{References}

1. Constitution of the Republic of South Africa Act No. 108; 1996. Available from: https://www.ru.ac.za/media/rhodesuniversity/content/ humanresources/documents/employmentequity/Constitution $\% 20 \mathrm{of} \% 20$ the \%20Republic\%20of\%20South\%20Africa\%201.pdf. Accessed April 20, 2017.

2. Department of Health, KwaZulu-Natal. White Paper on Transformation in the Public Service; 1997.

3. Govender S. The Role or Leadership in Healthcare Service Delivery at Addington Hospital [dissertation]. Durban, South Africa: University of KwaZulu-Natal; 2013.

4. Ndlovu ES. Evaluating Public Sector Service Delivery at KwazuluNatal Provincial Hospitals: A Case Study of the Durban Metropolitan and iLembe Region [dissertation]. Durban, South Africa: University of KwaZulu-Natal; 2012.

5. Senanayake P. Accountability and good governance are essential to deliver health services. B World Health Organ. 2006;84:662-663.

6. Naidoo G. Leadership and Governance for a Sustainable Public Service. The Case for Selected South African Public Service Organizations [dissertation]. Pretoria, South Africa: University of Pretoria; 2005.

7. McAlearney AS. Leadership development in healthcare: a qualitative study. J Organ Behav. 2006;27:967-982.

8. Naidoo G, Xollie T. The critical need for an integrated leadership approach to improve service delivery by the South African Public Service. J US-China Public Admin. 2011;8:1-15.

9. Naidoo G. Strengthening senior management skills in the South African public service: a rationale for strategic leadership. J Public Admin. 2009;44:4-14.
10. Boaden RJ. Leadership development: does it make a difference? Leadership Org Dev J. 2006;27:5-27.

11. Pretorius EM. The Role of Leadership in Enhancing Service Delivery in Local government [dissertation]. Johannesburg, South Africa: University of Johannesburg; 2006.

12. Nobin BE. An Analysis of the Theory and Practice of Leadership in Education with Particular Reference to Superintendents of Education (management) in the eThekwini region of KwaZulu-Natal Department of Education [dissertation]. Durban, South Africa: University of KwaZulu-Natal; 2004.

13. Schmitt M. Leadership and Healthcare Performance [dissertation]. Charlottesville, VA, USA: Virginia University; 2012.

14. Jasper M, Jumaa M. Effective Healthcare Leadership. Oxford: Blackwell Publishing; 2005.

15. Hussain HK, Talib NA, Shah IM. The impact of transformational leadership on job satisfaction and organizational innovation in Iraqi Higher Education. Int Bus Man. 2015;9:1274-1280.

16. Shriberg D, Shriberg A. Practising leadership. Principles and Applications. 4th ed. Hoboken, NJ, USA: Wiley; 2011.

17. Al Khattab S, Aborumman AS. Healthcare service quality: comparing public and private hospitals in Jordan. Int Bus Man. 2011;5:247-254.

18. Fealy GM, McNamara MS, Casey M, et al. Barriers to clinical leadership development: findings from a national survey. J Clin Nurs. 2011;20: 2023-2032.

19. Kumar S, Adhish VS, Deoki N. Making sense of theories of leadership for capacity building. Indian J Comm Med. 2014;39:82-86.

20. Jooste K. Leadership in Health Services Management. Lansdowne, South Africa: Juta; 2003.

21. Charlton G. Leadership. The Human Race. 2nd ed. Cape Town, South Africa: Juta; 1993.

22. Grol R, Baker R, Moss F. Quality improvement research: understanding the science of change in health care. Qual Safety Health Care. 2002;11: $110-111$.

23. Wong CA, Cummings GG. The influence of authentic leadership behaviors on trust and work outcomes of healthcare staff. J Leadersh Stud. 2009;3:6-23.

24. Kerfoot K. Authentic leadership. Medsurg Nurs J. 2006;15:319-320.

25. Klenke K. Authentic leadership: a self, leader, and spiritual identity perspective. Int J Leadersh Studies. 2007;3:68-97.

26. Armstrong M. Armstrong's Handbook of Management and Leadership. 3rd ed. London, UK: Kogan Page Limited; 2012.

27. Yukl G. Leadership in Organizations. 7th ed. Philadelphia, PA, USA: Pearson Education; 2010.
Journal of Multidisciplinary Healthcare

\section{Publish your work in this journal}

The Journal of Multidisciplinary Healthcare is an international, peerreviewed open-access journal that aims to represent and publish research in healthcare areas delivered by practitioners of different disciplines. This includes studies and reviews conducted by multidisciplinary teams as well as research which evaluates the results or conduct of such teams or health

\section{Dovepress}

care processes in general. The journal covers a very wide range of areas and welcomes submissions from practitioners at all levels, from all over the world. The manuscript management system is completely online and includes a very quick and fair peer-review system. Visit http://www.dovepress.com/ testimonials.php to read real quotes from published authors. 